\title{
Examination of living Sertoli cells in normal and hypospermatogenic men
}

\author{
K.-O. Söderström and V. Nikkanen* \\ Department of Pathology, University of Turku, SF-20520 Turku, 52, and \\ * Department of Obstetrics and Gynecology, Turku University Central Hospital, \\ SF-20500 Turku 50, Finland
}

\begin{abstract}
Summary. The functional state of living Sertoli cells can be assessed by using transillumination and phase-contrast microscopy. In tissue from hypospermatogenic men the Sertoli cells contained more lipid droplets than in normal cases and sometimes whole degenerative cells.
\end{abstract}

\section{Introduction}

Phagocytosis of residual bodies and degenerating germ cells is one of the many functions of the Sertoli cells in the seminiferous epithelium. Light and electron microscope investigations have revealed that normal human Sertoli cells have a different appearance according to the type and amount of their cytoplasmic inclusions (Schultze, 1974). In most cases they contain small osmiophilic fat droplets or lucent fat vacuoles. No correlation has been shown between the appearance of the Sertoli cells and the stages of spermatogenesis in man. It has been reported that the Sertoli cells show marked morphological alterations in association with spermatogenic arrest and hypospermatogenesis (Schultze, Holstein, Schinen \& Körner, 1976). The biopsy specimen of a hypospermatogenic man showed normal spermatogenesis in many tubules, but electron microscope studies revealed that mature spermatids were phagocytosed by Sertoli cells, as illustrated by numerous pleomorphic, osmiophilic phagolysosomes within the cytoplasm (Schultze et al., 1976). Human spermatogenic cells have been studied with the transillumination technique and by phase-contrast microscopy (Nikkanen, Söderström \& Parvinen, 1978). In the present study these techniques were used for human Sertoli cells.

\section{Materials and Methods}

The biopsies were taken from 6 patients with hypospermatogenesis and severe oligospermia. The normal control samples were obtained from patients in association with a reparative operation of varicocoele. All patients had normal serum levels of FSH and testosterone. The seminiferous tubules were dissected free from the interstitial tissue and observed in transmitted light in a preparation microscope. The same pieces of the tubules were then transferred to a glass slide and squashed beneath a coverslip to produce a monolayer of cells for examination by phase-contrast microscopy (Nikkanen et al., 1978).

\section{Observations}

The transillumination picture of the seminiferous tubules of patients with hypospermatogenesis was not very different from that of normal men (see Nikkanen et al., 1978: Plate 1). The seminiferous tubules of normal men usually show irregular, faint light absorption, with small darker spots caused by the maturation-phase spermatids. In the hypospermatogenic material some large dark spots were also occasionally seen near the basal lamina but in histological sections of the same specimens no abnormalities could be seen. These dark spots seemed to be 
degenerating spermatogenic cells. However, the phase-contrast appearance of the Sertoli cells differed from that of Sertoli cells of normal men in which there were moderate amounts of bright phase-negative small lipid droplets (Pl. 1, Fig. 1). In the hypospermatogenic tissue the amount of lipid in the Sertoli cells was greatly increased (PI. 1, Figs 2 and 3). Normally, the lipid droplets of the Sertoli cells appear in the phase-contrast microscope to be of relatively uniform size and are clearly separated from each other. When the phagocytosing activity has increased, the Sertoli cells contain lipid droplets of various sizes and the bright phase-negative material is not always homogeneous in structure (Pl. 1, Figs 2, 3 and 5). The lipid droplets are so numerous that they seem to be in contact with each other and to form conglomerates. The Sertoli cells also seem to phagocytose entire cells of the germ cell line (Pl. 1, Figs 2 and 5). The cells phagocytosed by the Sertoli cells are altered in their phase-change characteristics and this makes their accurate recognition difficult, e.g. Pl. 1, Fig. 2 in which the phagocytosed cell is probably a young spermatid.

Degenerating primary spermatocytes were seen in patients with severe hypospermatogenesis (Pl. 1, Fig. 4). The chromosomes, as well as the cytoplasmic structures, were more prominent than in normal testis and this was considered to be the first signs of cell degeneration detectable by phase-contrast microscopy. As the next step of cell degeneration, the entire cell is phagocytosed by a Sertoli cell and the size of the cell is considerably reduced (Pl. 1, Fig. 5). The chromosomes are distinguishable in this case, suggesting that this cell is degenerating in the primary spermatocyte stage or in association with the meiotic divisions. Whenever phagocytosed cells were seen inside the Sertoli cells the cytoplasmic lipid content of the Sertoli cells was also increased.

\section{Discussion}

In fresh and macerated human testicular material the Sertoli cells exist as individual units (Rolshoven, 1940) and have an ability to phagocytose degenerating cells of the germ cell line (Roosen-Runge, 1955; Bawa, 1963). It can safely be assumed that an increase of the phagocytosing activity of the Sertoli cells reflects early degenerative changes of the germinal epithelium and that evaluation of the condition of the Sertoli cells in biopsy specimens would be of value.

Electron microscopy is superior to light microscopy for evaluating the phagocytosing activity of the Sertoli cells because more details of the process are revealed (Schultze et al., 1976). However, electron microscopy is time consuming and not routinely used in andrology laboratories and more simple methods for evaluation of the functional stage of the Sertoli cells are needed. Phase-contrast microscopy could fill this gap. The reason for the phagocytosis of the degenerating germ cells remains unsolved.

\section{References}

Bawa, S.R. (1963) Fine structure of the Sertoli cell of the human testis. J. Ultrastruct. Res. 9, 459-474.

Nikkanen, V., Söderström, K.-O. \& Parvinen, M. (1978) Identification of the spermatogenic stages in living seminiferous tubules of man. J. Reprod. Fert. 53, 255-257.

Rolshoven, E. (1949) Die funktionelle polymorphie des Sertoli-syncytiums und ihr zuzammenhang mit der spermatogenese. Z. Zellforsch. mikrosk. Anat. 31, 156-169.
Roosen-Runge, E. (1955) Untersuchungen über die degeneration samenbildender zellen in der normalen spermatogenese der ratte. Z. Zellforsch. mikrosk. Anat. 41, 221-235.

Schultze, C. (1974) On the morphology of the human Sertoli cell. Cell Tiss. Res. 153, 339-355.

Schultze, C., Holstein, A.F., Schinen, C. \& Körner, F. (1976) On the morphology of the human Sertoli cells, under normal conditions and in patients with impaired fertility. Andrologia 8, 167-178. 
PLATE 1
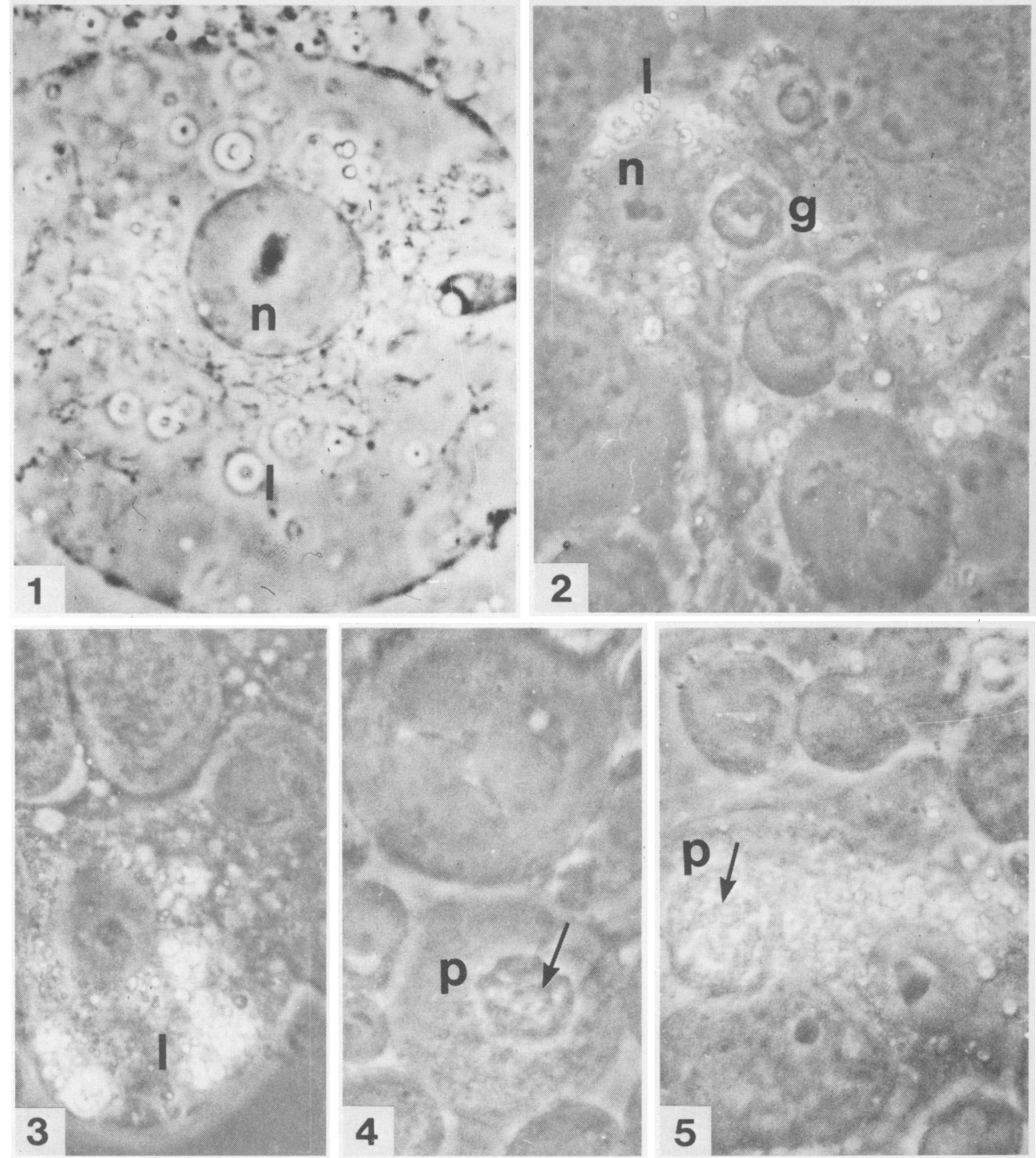

Fig. 1. A phase-contrast micrograph of a normal Sertoli cell. n, Sertoli cell nucleus; 1, lipid droplet. $\times 1080$.

Fig. 2. A phase-contrast micrograph of a Sertoli cell from a patient with hypospermatogenesis. The Sertoli cell has phagocytosed a whole degenerating germ cell $(\mathrm{g}) .1$, lipid droplet; $\mathrm{n}$, Sertoli cell nucleus. $\times 1080$.

Fig. 3. A phase-contrast micrograph of a Sertoli cell from a patient with hypospermatogenesis. The Sertoli cell contains numerous lipid droplets (1). $\times 1080$.

Fig. 4. A phase-contrast micrograph of a degenerating primary spermatocyte (p), containing chromosomes (arrow). $\times 1080$.

Fig. 5. A phase-contrast micrograph from the same patient as in Fig. 4. The picture shows a more advanced stage of the cell degeneration where the dying cell $(p)$ is phagocytosed by a Sertoli cell. The chromosomes are arrowed. $\times 1080$. 